\title{
Editorial \\ 10th Anniversary of Applied Sciences Invited Papers in Civil Engineering Section
}

\author{
Eugene J. OBrien
}

Citation: OBrien, E.J. 10th Anniversary of Applied Sciences Invited Papers in Civil Engineering Section. Appl. Sci. 2021, 11, 5918. https:/ /doi.org/10.3390/app11135918

Received: 2 June 2021

Accepted: 17 June 2021

Published: 25 June 2021

Publisher's Note: MDPI stays neutral with regard to jurisdictional claims in published maps and institutional affiliations.

Copyright: (C) 2021 by the author. Licensee MDPI, Basel, Switzerland. This article is an open access article distributed under the terms and conditions of the Creative Commons Attribution (CC BY) license (https:// creativecommons.org/licenses/by/ $4.0 /)$.
School of Civil Engineering, University College Dublin, D04 V1W8 Dublin, Ireland; eugene.obrien@ucd.ie

Applied Sciences has achieved a major milestone this year: it is the 10th anniversary of the journal. To celebrate the occasion, this Special Issue of the Civil Engineering section is being published, featuring leading authors in Civil Engineering. It features advances in diverse areas of this field, reflecting the breadth of Civil Engineering. Authors who are well-known experts in their fields of study have published contributions in Structures, Geotechnics, Transportation and in the cross-cutting topic of Optimization.

There are a number of papers on Structural issues, with applications to both bridges and buildings. Pancella and Luongo [1] consider an analysis issue for box girder bridges. Highly sophisticated analysis models are widely available but their use sometimes distracts the user from the underlying bridge behavior-its response to load. It is very welcome to have a paper addressing such a fundamental analysis issue as the nature of the torsional/distortional behavior of this bridge form. As box girders become larger and more slender, distortion is likely to become more significant and it is good to have simple models that can provide designers with insights into its significance. Iqbal et al. [2] also make a contribution to the Bridge Engineering literature, this time on the issue of fatigue. Hot-spot stresses are a particular analytical challenge and are a design issue for orthotropic bridge decks. Iqbal et al. present a guideline for the calculation of these stresses, which can be used to better evaluate the fatigue life of these all-important details. They suggest that shell elements produce more consistent hot-spot stress results than solid elements for stress at two important locations: at the rib toe and the highly non-linear deck toe.

The contribution of Zhao et al. [3] also relates to bridges but is on the subject of health monitoring, as opposed to design. One of the greatest challenges in bridge health monitoring is the variability of the applied traffic load. It is difficult to interpret data when they include the responses to vehicles with very different weights and numbers of axles. Zhao et al. address the challenges of axle detection-finding the number of vehicle axles, where they are on the bridge and tracking their locations during the vehicle crossing event. The technique has the potential to greatly enhance bridge health monitoring by allowing measured responses to be broken down into equivalent single-axle responses, thereby facilitating the integration of data from a variety of different vehicles.

Buildings are the subject of two Structures papers. Scaramozzino et al. [4] review recent trends in tall building design towards diagrid structures. Simplified methodologies for preliminary analysis and design are reported, as well as the issue of using the pattern to optimize the structural response. Complicating issues are also addressed, including local deformability, stability and shear-lag. This seems to be an active area of development, with mention of twisted, tapered, tilted and freeform diagrid towers and hexagrids. Sciomenta et al. [5] consider the responses of much smaller, timber blockhaus structures to earthquake loading. With increasing emphasis being placed on renewable materials, timber seems likely to be the focus of increasing interest in construction. Blockhaus structures have particular potential but there are also challenges due to their intrinsic geometrical and mechanical features, such as stacking of logs and door/window openings. Sciomenta et al. propose a simplified method of analysis to assess their resistance to earthquake loading and validate the results through comparison with more sophisticated finite element analyses. 
Three papers relate to transportation infrastructure. Kaewunruen et al. [6] investigate the environmental implications of a high-speed railway tunnel in China. They find that the materials used during construction account for over $97 \%$ of the $\mathrm{CO}_{2}$ emissions of the life-cycle. Further, construction consumes over $44 \%$ of the life-cycle energy, with maintenance processes accounting for most of the rest. Stawska et al. [7] review the accuracy of truck weighing techniques, both static and weigh-in-motion (WIM). Vehicle weight data are widely used for the design of pavements and for the assessment of bridge safety. Stawska et al. analyze data that have been weighed using four different technologies: weigh station, portable scales, bridge WIM and pavement (strip sensor) WIM. The conclusion is that all four systems produce results within the required and expected accuracy. Hajializadeh et al. [8] report on a study where the bridge WIM concept was extended to the problem of weighing trains. Four trains were statically weighed to test the results. It was found that, unlike trucks, the train speed cannot be assumed to remain constant during the bridge crossing event. When the system was corrected to allow for variable speed, the accuracy was found to be very good.

Two papers consider the topic of multi-objective decision support methods. Bruen [9] reviews the literature to determine what approaches are used for Civil Engineering applications. He concludes that, while many methods are available, a small number dominate usage in issues relating to sustainability, environment, risk, safety and project management. The Analytic Hierarchy Process seems to be particularly popular. When he widened his search to other topics, such as bridge design and transportation, the results were quite different, with a more complete range of supporting software available. Stipanovic et al. [10] consider the application of one of these methods of multi-objective decision-making to a railway network maintenance problem. In the context of slope stability, they propose an optimal approach to management, considering the competing objectives of user cost (asset availability), asset owner cost and structural reliability. Multi-attribute utility theory is used to balance the priorities of the competing objectives in a harmonious way, giving a holistic means of ranking assets and ultimately prioritizing maintenance activities.

It can be seen that this special anniversary issue covers a very wide range of topics. In addition to traditional fields such as Structures and Geotechnics, Civil Engineers are often concerned with 'big picture' issues such as environmental implications and sustainability. They can also find themselves in unexpected fields, such as weighing trucks or trains, which have implications for Civil Engineering infrastructure. This Special Issue reflects the wide diversity in this branch of Engineering.

Funding: This research has received no external funding.

Conflicts of Interest: The author declares no conflict of interest.

\section{References}

1. Pancella, F.; Luongo, A.A. Minimal GBT Model for Distortional-Twist Elastic Analysis of Box-Girder Bridges. Appl. Sci. 2021, 11, 2501. [CrossRef]

2. Iqbal, N.; Fang, H.; Naseem, A.; Kashif, M.; DeBacker, H. A Numerical Evaluation of Structural Hot-Spot Stress Methods in Rib-To-Deck Joint of Orthotropic Steel Deck. Appl. Sci. 2020, 10, 6924. [CrossRef]

3. Zhao, H.; Tan, C.; OBrien, E.J.; Uddin, N.; Zhang, B. Wavelet-Based Optimum Identification of Vehicle Axles Using Bridge Measurements. Appl. Sci. 2020, 10, 7485. [CrossRef]

4. Scaramozzino, D.; Lacidogna, G.; Carpinteri, A. New Trends towards Enhanced Structural Efficiency and Aesthetic Potential in Tall Buildings: The Case of Diagrids. Appl. Sci. 2020, 10, 3917. [CrossRef]

5. Sciomenta, M.; Rinaldi, V.; Bedon, C.; Fragiacomo, M. Application of Modal-Displacement Based Design Method to Multi-Story Timber Blockhaus Structures. Appl. Sci. 2020, 10, 3889. [CrossRef]

6. Kaewunruen, S.; Sresakoolchai, J.; Yu, S. Global Warming Potentials Due to Railway Tunnel Construction and Maintenance. Appl. Sci. 2020, 10, 6459. [CrossRef]

7. Stawska, S.; Chmielewski, J.; Bacharz, M.; Bacharz, K.; Nowak, A. Comparative Accuracy Analysis of Truck Weight Measurement Techniques. Appl. Sci. 2021, 11, 745. [CrossRef]

8. Hajializadeh, D.; Znidaric, A.; Kalin, J.; OBrien, E.J. Development and Testing of a Railway Bridge Weigh-in-Motion System. Appl. Sci. 2020, 10, 4708. [CrossRef] 
9. Bruen, M. Uptake and Dissemination of Multi-Criteria Decision Support Methods in Civil Engineering-Lessons from the Literature. Appl. Sci. 2021, 11, 2940. [CrossRef]

10. Stipanovic, I.; Zaharah, A.B.; Reale, C.; Gavin, K. A Multiobjective Decision-Making Model for Risk-Based Maintenance Scheduling of Railway Earthworks. Appl. Sci. 2021, 11, 965. [CrossRef] 